\title{
Reflective Teaching: An Approach to Enrich the English Teaching Professional Practice
}

\section{Reflexión: un acercamiento para enriquecer la práctica profesional en la enseñanza de inglés*}

\author{
Marian Lissett Olaya Mesa \\ marian.olaya@uptc.edu.co \\ Universidad Pedagógica y Tecnológica de Colombia, Sogamoso, Colombia
}

This study provides an overview and exploration of 23 national and international reflective teaching research reports. The purpose of this study is to determine the extent that reflective teaching can become a strategy for language teaching professional development. Based on content analysis four main topics emerged: (a) reflective teaching as an approach to enhance the language profession; (b) impact on teacher's performance; (c) support, time, and effort; and (d) in-service professional development. Conclusions indicated that reflective teaching is an alternative to raise awareness about English language teaching, and as a means to encourage teachers to open their minds, update their teaching methodologies, and make adjustments to their lessons.

Key words: English teaching professional practices, professional development, reflective teaching, reflective teaching strategies.

El interés principal de este estudio es explorar la enseñanza reflexiva para contribuir con el mejoramiento de las prácticas profesionales de los profesores de inglés. Este estudio exploratorio se centra en la identificación y explicación de las estrategias de enseñanza reflexiva y la comprensión de veintitrés informes de investigación llevados a cabo en ámbitos nacionales e internacionales. Basado en un análisis

\footnotetext{
* $\quad$ Received: May 24, 2017. Accepted: February 8, 2018.

How to cite this article (APA 6th ed.):

Olaya Mesa, M. L. (2018). Reflective teaching: An approach to enrich the English teaching professional practice. HOW, 25(2), 149-170. https://doi.org/10.19183/how.25.2.386.

This article is licensed under a Creative Commons Attribution-NonCommercial-NoDerivatives 4.0 International License. License Deed can be consulted at https://creativecommons.org/licenses/by-nc-nd/4.0/.
} 
de contenido cuatro áreas de exploración emergieron: (a) las contribuciones y los usos de la enseñanza reflexiva como enfoque, (b) impacto en el desempeño del docente, (c) apoyo, tiempo y esfuerzo y (d) el entrenamiento de profesores en prácticas reflexivas. Los resultados indicaron que la enseñanza reflexiva parecía ser la mejor alternativa para crear conciencia y como un medio para animar a los profesores a abr ir sus mentes, actualizar sus metodologías de enseñanza y hacer ajustes a sus lecciones.

Palabras clave: desarrollo profesional, enseñanza reflexiva, estrategias de enseñanza reflexiva, prácticas profesionales en la enseñanza de inglés.

\section{Introduction}

The strengthening of teachers' professional development in Colombia has become an important concern for the Colombian Ministry of Education (MEN) within the bilingual educational policies and programs developed so far. For example, the program "Colombia Bilingüe 2014-2018” which focuses on three main strategies: pedagogical design, English language teachers' professional development, and English language teaching materials.

Improving English language professional practices requires training teachers in materials and curriculum development, teachers' evaluation, and English language proficiency skills, as MEN has indicated. Therefore, teacher training becomes one of the key actions to fulfill the program goals.

The MEN assessed English language teachers in 2005 with the Quick Placement Test (QPT), designed by the University of Cambridge; then, results showed a very low level of language proficiency. However, many concerns about the validity of the assessment analysis arose from Colombian language teachers, since the test mode familiarity could have an impact on test results. The fact that Colombian English language teachers had a low English language level persuaded the national government to start implementing the In-service Certificate in English Language Teaching (ICELT) and the cascade model as the main professional development strategies for language teachers. Therefore, the model was conceived and Bett (2016) stated his opinion:

The cascade model is often founded on the notion of an "expert" delivering valuable ideas to often "inexperienced" or "ignorant" teachers. Teachers have unique needs and experiences and when these are ignored or rubbished at the altar of perceived superior advice, the process is set to fail from the start. (p. 4)

González (2007) argued that "the ICELT model favors the adoption of a top down model in which teachers do not have voices, are not invited to teach reflectively, and are not agents of their own development" (p. 317). González further states that "the ICELT model does not advocate the need to have autonomous reflective practitioners that participate in networks... Its most notorious limitation is probably the failure to recognize and value 
teachers' expertise and knowledge outside the dominant discourses" (p. 319). Cárdenas, González, and Álvarez (2010) "proposed considering teachers' development, not training, which would imply an ongoing process" (p. 54); it means that professional development programs which consider teachers' experiences, interests, and collaborative work are more effective because they engage language teachers in a deep and continuous reflective teaching process.

Considering González's and other researchers' reflections on the program proposed by the MEN, it can be said that the implementation of ICELT stated by MEN is inadequate as the main option for professional development for language teachers because it does not take into account the real Colombian teaching context. According to Castro and Martinez (2016):

Teachers' professional development is an ongoing process in which teachers engage to transform some of their conceptions and practices around pedagogy, methodology, and didactics in order to find new roads that allow them to meet the needs and interests of their own contexts." (p. 40)

From that sense, language professional development programs should strive to improve language competence and teaching methodologies that meet the standards of excellence in education.

Consequently, there is a need for appropriate professional development programs for Colombian language teachers that meet real requirements of the constantly changing Colombian educational system. This implies that English language teachers become more reflective in such a way that their practices improve as well as learners' performance. In that sense, the purpose of this study was to explore how the inclusion of reflective teaching in teaching practices may enhance the professional development process for English language teachers as reflective teaching involves going beyond teaching instructional techniques. Teachers who explore their attitudes towards the teaching profession through critical reflection can benefit their professional practices as well as the improvement of their students' learning education.

Considering what was said above, this exploratory study contemplated the need for teachers to be engaged in a reflective process that at the end is going to truly impact their classrooms and the students; to think about their teaching and analyze what could be improved becomes a fundamental component of teachers' professional growth to provide learners with a better language teaching process, not only to achieve the requirements of MEN, but also to improve English language teachers' professional practices in a reflective way. English language teachers may monitor their own teaching instruction as a continuing improvement of language education. Teachers could analyze difficulties or new trends in their classroom and look for different teaching alternatives. Moreover, teachers can expand their teaching knowledge-base, and promote effective language acquisition to have a positive 
learning environment to be able to understand their learners' needs and interests. From that perspective, I embarked on this exploratory study to find practical possibilities to benefit the professional development programs that facilitate the English language teachers' improvement in the Colombian context; consequently, reflective teaching was found as a possible and effective strategy to be implemented by language teachers.

I explored 23 research studies focused on reflective teaching strategies in the English teaching process to enhance English language professional practices. I attempted to answer the following research question: To what extent can reflective teaching become a strategy to enrich the English teaching professional practice?

\section{Theoretical Framework}

\section{Reflective Teaching: Significant Definitions}

This section is organized in two parts; first, the literature review provides a summary of what reflective teaching is; its benefits and challenges and how reflective teaching has been interpreted and implemented, and second how the incorporation of reflection serves as professional development to enhance English language teaching professional practices.

Reflective teaching applied in the classroom is an imperative interpretation of how language education may improve. Reflective teaching or becoming critical of oneself has gained importance in the professional practice of English language teachers as a result of the benefits it can have on teaching practices and on teachers' professional life. Dewey introduced the term reflective teaching in 1933; he considered it to be

An active and deliberative cognitive process that involves sequences of interconnected ideas that take into account underlying beliefs and knowledge. School's actions became routine and needed to change. Reflection is considered as a thinking process, resulting in creating alternatives of teaching. He further stated that teachers who are unreflecting about their teaching often uncritically accept this everyday reality in their schools and concentrate their efforts on finding the most effective and efficient means to solve problems. (As cited in Pedro, 2006, p. 130)

In this regard, the idea that teachers need reflection not only to change their everyday routines within a classroom, but also to realize what problems are arising should become a current belief for language teachers. It is common to recognize that teachers tend to implement routinized teaching methods, perhaps because of their teaching beliefs or lack of professional development.

Dewey's theory allowed me to understand that this process of reflection is not an easy one. Being reflective requires an understanding of why certain actions appear in the way teachers teach, where knowledge-based foundations come from, their language skills, and the 
will to change. It means that reflection should involve more than a simple reflective session or training. It is suggested that teachers should be able to accept and consider other current teaching ideas which can be found by reading recent research reports or by participating in any professional development program.

Zalipour (2015) writes:

Reflective practice for teaching is for those teachers who are disposed to think about their teaching practices, and are willing to put reflective practice into action. Reflective practice challenges teachers who have unquestioned assumptions about good teaching, and encourages them to examine themselves and their practices in the interest of continuous improvement. (p. 4)

It implies teachers' commitment to study their teaching practices to make changes based on weaknesses and develop action plans to improve the quality of their education instruction. Impedovo and Khatoon Malik (2016) stated that

To be a reflective practitioner, a teacher can implement different strategies. They could, for example, analyze and question happenings within the teaching-learning context; show consideration for feelings and behaviors; keep a regular or daily record of significant events; share stories about students' learning; ask colleagues and students' families for their insights; or read professional literature to learn more about changing the environment and materials to support students' learning. (p. 102)

Zalipour (2015) and Impedovo and Khatoon Malik (2016) agree that reflection is a process of rethinking and analyzing certain actions in class so students and teachers reach their teaching and learning objectives. These contributions are similar to Dewey's definition.

Additionally, MacKinnon's reflective cycle, which consisted of three phases: initial problem setting, reframing, and resolution (as cited in Tairab, 2003, p. 3), was derived from Schön's (1987) conception of reflection: framing and reframing. The previous contributions on reflective teaching enable teachers to analyze their actions in the sense of providing outcomes. Al-Issa and Al-Bulushi (2010) argued: "for reflection on teaching and learning to be effective, it has to be systematic and public (making one's teaching and work accessible for critical peer review and use)" (p. 42). It means the incorporation of reflection has to be a daily process, a vital part of the English language teaching profession to see effective changes in the classroom. Further, Al-Issa and Al-Bulushi stated that "trainers have the important task of educating themselves in depth about reflection and reflective teaching, which should have positive implications for their trainees' performance" (p. 60).

In the Colombian context reflective teaching appears as the ability to think about the teaching performance in the classroom. According to Trujillo (2015): 
It is not only to reflect about the everyday doing as a teacher, it is to make a decision and implement this decision to really improve teaching actions and acquire knowledge from experience as a teacher and promote students' learning. (p. 29)

At this point, it is necessary to add that reflection has been contemplated in the national context as a way to create a learning environment to motivate teachers not only to examine their classroom performance, but also to foster their research practices. In addition to this, supporting teachers by professional development programs is an open door for the improvement of English language teaching and learning in Colombia. Reflective teaching, by international researchers, has been considered as an essential component of teaching and learning a language. According to Ahmad et al. (2013), "reflectivity is one of the characteristics of effective teachers" (p. 73). In that sense, reflection encourages language teachers to be more competent because they develop critical thinking and problem-solving skills that play a vital role in the effectiveness of language education.

\section{Challenges and Benefits of Reflective Teaching}

Surely teachers are required to make hundreds of decisions in a single class day as they observe their students' learning as well as each student's style of learning. Therefore, they may keep observing problems and issues of education in the same way; as part of their daily classes and do not find any other way to address problem issues. The challenge here is to provide language teachers with the opportunity to start analyzing themselves as educators. According to Ditchburn (2015), "creating opportunities for pre-service teachers (PSTs) to critically reflect on and theorize about their practice is frequently regarded as an essential component of professional experience" (p. 94). This quote suggests that language teachers need chances to analyze the way they have been teaching and notice they do not have to make a decision just because a problem appears. Instead, there has to be an action plan to uncover possible issues and to have a second plan. In other words, teachers should implement continuous phases of reflection to identify what is going on in the classroom as an opportunity to improve their professional practices.

When referring to the reflective teaching processes, responsibility appears as an important component to facilitate the enrichment of English language professional practice. The responsibility of teachers' actions regarding the effects on students' learning process is considered an imperative component to change English language teaching. It means the responsibility to offer high-quality instruction and understand students' attitudes towards their language learning performance is a vital component so language learners will feel more confident when trying to produce the English language. The process of reflection might have teaching consequences on the whole academic community and on teachers themselves. Attitudes, perceptions, emotions, and feelings can be modified when involved in re-thinking how they perceive language education. 
It means when language teachers are motivated and implement different activities, learners will be motivated too and their perceptions and attitudes towards their learning process will transform into positive aspects too. According to Tairab (2003), "reflection was found to be characterized by the nature of reframing which occurred over the teaching practice period" (p. 18). In that sense, certain actions and attitudes would need adjustments; however, there are other more spontaneous actions that are not expressed which cannot easily be explained.

Tairab's (2003) contribution complements Dewey's initial conceptions; mainly because thinking and reflecting on teaching are needed as well as paying careful attention to what needs to be reflected upon; for example, teaching methods and learning styles. Hence, through the incorporation of reflection in the classroom, teachers can criticize their beliefs and actions to improve. That examination would be transformed into teaching contributions which allow a comprehensive awareness of what is possible in reflection and what we can do with those underpinnings.

In that sense, becoming critical about oneself means to analyze classroom outcomes and teaching procedures in a thoroughly and routinized way to reach specific objectives, including the improvement of the teaching practices. Besides, by implementing reflective teaching, Erginel (2006) concluded that "teachers were open and responsible while giving and receiving feedback. In this process, they accepted guidance wholeheartedly, in a mature manner underlining that feedback helped them raise their awareness towards their teaching and develop themselves professionally" (p. 86). Reflection can be interpreted in different ways. It is understood as what the teachers are able to do in the classrooms and what they can adapt to create a new perspective as regards their classroom actions.

English language teachers should be encouraged to reflect by themselves based on their personal interests, experiences, and kind of learners because, then, they can develop their full teaching potential. Shaping and facing the several challenges language teachers deal with in the classroom require an ongoing process of reflection, examination, and restructuration of the teaching instruction, students' learning styles and interests, the teaching context, the real problems and issues of the educative system in general.

Jerez (2008) noted that several skills are necessary to implement reflective teaching actions in the teaching profession. In her study, she reported that

Teachers' participation in the program served to allow teachers to raise awareness and question the need to reflect. It meant more thinking and observing their acting and making changes in their practice. It also enabled them to develop particular skills to become reflective such as to start working with colleagues, communicate ideas, look critically at their actions and evaluate the process they were following. (p. 103) 
In sum, she found out that reflective teaching is a process that requires preparing teachers to be able to assess their performance in class and provide specific action on their teaching practices.

In this respect, reflection as so far understood is a broad thinking process that involves not only being critical about one, but also evaluating teacher performance. It means to be able to empower teachers in a society in constant re-creation. It underlines how important reflective teaching is for the transformation of a community and for learners, specifically, who are becoming more active in their learning process. Following that perspective, Erginel (2006) noted that "reflective teaching on teacher education contributes to pre- and in-service teachers' meaning making processes by enabling them to consider different experiences and by interpreting these experiences in light of theory and own value judgments influenced by social factors" (p. 17). The previous contributions proved the benefits of the incorporation of reflection into the daily teaching practice which allows me to define reflection as an analytical and critical process of different actions, attitudes, and decisions in order to progress more efficiently in the teaching practices by the teachers.

Soisangwarn and Wongwanich (2014) argued that "reflective teaching is effective for professional teacher development in that it encourages the teacher to look at ways of managing the classroom and children from differing perspectives, based on assessment data" (p. 2505). From that perspective, reflective language teachers develop their teaching but also start doing research to gather important data about their teaching.

Another contribution to the discussion is provided by Mathew (2012) who stated that:

The practice of reflection involves critical examination of self-motivation and thinking. It is a move towards critical thinking to improve productivity in teaching and students' learning. Learning involves acquiring competence through action and experience while teaching involves engaging the learners in a process of activity that is likely to result in success of intended learning outcomes. Helping learners to understand the reasons for failures and creating awareness in self-correction can improve students' classroom performance. (p. 206)

From Mathew's (2012) arguments it is possible to say that reflective teaching as a critical examination of teachers' performances is mainly determined by the way they self-evaluate because the self-evaluation process requires a deep understanding of how language teachers teach and to try to find reasons for why they teach in certain ways.

\section{Reflective Teaching Process}

In Colombia, researchers have proposed different ways of practicing reflective teaching. Núñez and Téllez (2015) concluded that "reflection raises teachers' awareness of personal and professional growth by enhancing their discipline knowledge, pedagogical practices, 
and research projects as well as fostering self-confidence, creativity, and self-esteem" (p. 66). What Núñez and Téllez suggested is that the process of reflection helps not only to reinforce the English language instruction in the classroom but also teachers' personal and professional life. In this process of reflection teachers may start creating their own teaching materials and transforming their classroom into possible research projects.

Another aspect that builds the process of reflection in the Colombian educational system has been highlighted also by Viáfara (2005): "A reflective approach has been satisfactory in order to cope with many of the constraints in terms of time, resources and the difficult social situation of school students that generates concern and anxiety in future teachers" (p. 65). Within this perspective, reflecting on what is actually going on in public schools' settings (class size, culture background, and social status) should generate the transformation of giving valuable and viable alternatives to meaningful learning. It is evident that language teachers do not make the policies but they have the commitment to contribute to their professions. It means that an effective professional development practice should take into consideration the real teachers' needs as well as learners' interest and context.

\section{Reflective Teaching Strategies}

The main purpose of this section is to show how the process of reflective teaching can be incorporated to enhance English teaching professional practices within a classroom or in a whole academic community. In fact, reflective teaching helps teachers to be aware of what has to be changed or modified inside their classrooms. Along this literature exploration, readers would find some strategies-journals, lesson reports, video and audio recording, and selfobservation methods - that can be used in order to incorporate reflection into the personal professional practice. It is necessary to mention that I found some other important strategies suggested by several scholars such as video recordings, peer observation, portfolios, journals, lesson reports, questionnaires, analyzing critical incidents, and case analysis. However, the strategies mentioned in this section are selected as strategies for the implementation of reflective teaching in the daily teaching process by in- service teachers. These strategies were selected because first, teachers can implement them either by themselves or with the help of colleagues; they do not need any extra support. Second, they are easy to manage; for example, teachers can write in a journal what and how they feel after teaching a class and they can also have fun because teachers can take advantage of technology devices. Teachers can write their reflections on a blog and receive feedback from other teachers so that they can receive advice or suggestions on what they wrote. Third, in-service teachers can evaluate their teaching performance by videotaping and observing themselves after class. Fourth, English teachers develop a deep-thinking process to understand what and how they teach. Teachers can connect their teaching planning to their real teaching experiences. The implementation of any reflective teaching strategy requires that the teacher think of a topic that is going to 
be observed, read, or analyzed. Then, teachers must decide what they would do with that information. It is important to clarify that reflection requires outcomes; for example, a small project; or a different class. Finally, thanks to the results of the implementation of any of these strategies within a classroom, it may help teachers to improve their teaching practices. It means teachers can collect information, find an issue to be solved, and implement any action plan.

\section{Type of Study and Research Procedures}

This research project was conducted under the principles and theoretical considerations of exploratory research as I attempted to explore reflective teaching to have a better understanding of how it could actually provide English language teachers with possible solutions to grow professionally.

This research was initiated based on Ashour's steps (2008, p. 25) for conducting exploratory research. First, I started to identify the area (the incorporation of reflective teaching) to be explored and reflected on in order to get an understanding of the issue. This step was done through the exploration and analysis of the 23 research reports on how reflective teaching may help language teachers to improve professionally. Second, a constant reflection upon the sources was carried out; at this stage I built the characterization of sources in tables. Third, according to Allwright and Lenzuen (as cited in Ashour, 2008), monitoring became a matter of gathering naturally occurring data about whatever puzzled me. Fourth, direct action to generate data and the categorization of the analysis emerged; finally, the source analysis outcomes facilitated the design of a reflective teaching protocol (see Appendix) that would be offered to the community.

Based on the research question, the first exploratory stage was developed through the exploration of the literature of several sources from which 23 research reports were chosen. The selected studies were academic outcomes related to the reflective teaching strategies incorporation in schools and universities in public or private institutions. To do so, I conducted an online search using Google search and Science Direct. I found around 60 articles, institutional reports, and published journals not only in databases in Colombia but also in databases from Canadian, European, Indian, and Australian universities. Only 23 were selected based on the research question and objectives, and because of their importance in the English language and teaching community. More specifically, the articles needed to address research on reflective teaching, reflective teaching strategies, professional practices, and professional development. Table 1 shows the most relevant journals considered for the exploration. 
Table 1. Journals Used for the Literature Review

\begin{tabular}{|l|}
\hline International Journal of Research in Humanities, Arts and Literature \\
\hline Profile: Issues in Teachers' Professional Development \\
\hline HOW journal \\
\hline Íkala: Revista de Lenguaje y Cultura \\
\hline Canadian Center of Science and Education \\
\hline International Education Journal \\
\hline The Journal of Modern Thoughts in Education \\
\hline Social and Behavioral Journal of Teacher Education \\
\hline Academic Publisher \\
\hline Mediterranean Journal of Social Sciences \\
\hline
\end{tabular}

The following criteria were taken into account to select the 23 articles:

1. Research reports or theoretical papers written between 2008 and 2016.

2. Investigations conducted in and outside Colombia.

3. Research reports in which reflective teaching was the main construct and part of the pedagogical intervention.

4. Reports with the participation of in-service language teachers or in some cases pre-service teachers.

\section{Content Analysis: Characterization of Reflective Teaching Studies}

For the sake of brevity, a handful of representative studies, from the 23 selected, will be described next. However, I will discuss the ideas that are common to all the studies. The study by Tairab (2003) follows an interpretative paradigm based on Schön’s (1987) and his study reveals that:

If student teachers were able to learn through and from the process of reflection, then the practice of reflection should be seriously regarded as a viable methodology for professional growth and development of pre-service primary teachers and should carefully be considered as an essential element in the training of teachers. (p. 19) 
I also analyzed the study by Rayford (2010) whose purpose "was to describe the perceptions of elementary administrators and teachers from three states in the West regional area of the United States concerning reflective practice" (p. 7). Rayford concluded that:

It was evident that teachers believed reflection was important and worthwhile. They liked reflecting about their own teaching. The data showed that teachers often reflected in the midst of teaching during every lesson to make adjustments. Teachers felt that reflection helped them improve their teaching performance. Additionally, teachers felt that they needed time to reflect and preferred to dialogue/collaborate with peers. (pp. 75-76)

A difference between the previous studies and Rayford's is that this one was based on open-ended questions and the participants were not involved in any professional development program. I also explored Christodoulou (2010) who reflected on his teaching in a systematic way in order to (a) find out whether systematic self-reflection will reveal the most problematic areas in teaching and (b) to compare and analyze the benefits and drawbacks. He felt that even after seven years of teaching there were still many things he wanted to improve and work on. He also knew that most of the reflective work had to be done by himself in the first place, with some help from his pupils and perhaps his colleagues. After some months of self-reflection, he concluded that "it helped him to uncover the weak points in his teaching, their causes and give suggestions for improvement" (p. 69).

Mathew (2012) conducted a study in which he concluded that "reflective practices must involve an openness that requires teachers to challenge their assumptions and continue to improve skills needed for effective classroom instruction" (p. 209). It means that English language teachers might develop more skills than teaching after being involved in any reflective teaching training.

Self-reflection also appeared as an important component of reflection on the teaching practice of English as a second language. Becoming a critically reflective teacher was investigated by Saylag (2012), who highlights "the importance of personal beliefs and experiences that contribute to critical reflection as the distinguishing attribute of reflective practitioners" (p. 3848). In that sense, personal beliefs and experiences should be at the core of the process of reflection which, in turn, would serve to improve teaching and academic skills.

Another research project that serves as an example of how reflective teaching has been implemented was done in Malaysia and conducted by Ahmad et al. (2013) in which its purpose was "to investigate the perceptions of Community Based School teachers in district Chitral regarding the role of reflective practice in the improvement of their classroom teaching skills" (p. 74). Teachers in that study were provided with six months rigorous training in reflective practice. They were involved in a reflective teaching training in which the data were collected by a close-ended questionnaire. The participants also had the opportunity to 
understand how they were to reflect on and what topics to select. This kind of study allowed the population under the study to do a deep reflection and then analyze their perceptions about teaching.

One important finding by Ahmad et al. (2013) was that 90\% of the teachers were in favor of the statement that they reflect on their taught lesson after classroom teaching. A conclusion of their study was that:

Despite [the] difficulties ... reflective teachers focus on the [diversity of] learners and their needs in the real classroom environment. ... Reflective teachers are now self-observers and self-evaluators. This characteristic enables them to know their own actions and the problems of learners. (p. 80)

I want to highlight that teachers involved in Ahmad et al.'s study understood the importance of reflective teaching processes after participating and having training on that process.

Other important contributions to the topic are those studies by Colombian scholars such as Álvarez (2009), Camacho et al. (2012), Cote (2012), Fandiño (2011), Giraldo (2014), and Jerez (2008). Their research was conducted both in public and private institutions and they all establish that it is imperative that teachers become involved in systematic and reflective activities so that they can become aware of their performance and progress.

To sum up, reflection is a way to enhance teacher's performance in the classroom. However, it is also important to highlight that to make reflective teaching happen it should be a process in which teachers receive training because the adoption of reflective teaching strategies should become a habit, not an imposed policy by head administrators. Autonomous teachers have many benefits when they start seeing the need to reflect. Teachers also uncover wrong beliefs, shape old perceptions in education, cheer motivation and self-esteem, and foster team work.

\section{Categorization of Data}

After the content analysis, the following categories emerged: Reflective Teaching as an Approach to Enhance the Language Profession; Impact on Teachers' Performance; Support, Time, and Effort; and In-service Professional Development.

\section{Reflective Teaching as an Approach to Enhance the Language Profession}

It is significant to say that along the exploration of the 23 research reports, reflective teaching is considered as an alternative to improve the teaching practices, to enhance certain 
teachers' competencies (e.g., knowledge base and language skills), and to reinforce English language teaching in general. The studies analyzed tend to show that reflective teaching can be seen as a different approach to encourage teachers to become more critical of their daily performance. Ahmad et al. (2013) note this when they state that "reflective teachers are effective teachers" (p. 80). Teachers open their minds and uncover issues that keep appearing in their daily instruction, but which are not easily observable, and come up with solutions. Reflection consists of a process which allows teachers to provide an active learning environment for learners and it should therefore become a habit, which can be targeted with development programs.

\section{Impact on Teachers' Performance}

The strong point when incorporating reflection is how language teachers may benefit. According to Mizell (2010), "the effectiveness of professional development depends on how carefully educators conceive, plan, and implement it. There is no substitute for rigorous thinking and execution" (p. 10). This means that teachers have to be committed, dedicate much time to observe, analyze, and set action plans to actually improve the way they have been teaching.

Bailey (1997) offers the following three reasons for practicing reflective teaching:

Reflective teaching is extremely valuable as a stance, a state of mind, a healthy, questioning attitude toward the practice of our profession. It creates a context which promotes professional dialogue as we accumulate substance for our stories and it helps to clarify our thinking. (p. 15)

Correspondingly, the aim of professional development is focused on the improvement of teachers' actions to have effective outcomes of English language learners; it means if language teachers are conscious of an effective language education bearing in mind how learners learn; the results would easily be seen in the classroom. In particular, promoting active and viable professional development for English language teachers in Colombia is essential to provide language teachers with a pertinent professional development where their suggestions, proposals, real needs, and reflection of the actions taken will be heard.

However, after considering what the scholars have said, I can conclude that becoming a reflective teacher is not an easy process; it requires support, time, and effort.

\section{Support, Time, and Effort}

Within the reflective teaching processes, the support for language teachers constitutes a vital factor to enhance the incorporation of reflective teaching to grow professionally. One of the main aspects within this support is the need of teacher development programs that satisfy local teachers' 
needs. González (2007) proposed a situated model for professional practice for English language teachers. She affirmed that "there is a need for new forms of teacher development programs that respond to the requirements of different teachers, teacher educators, professional development agendas, and methodologies because the ones proposed are not sensitive to our educational needs" (p. 326). Teachers require the support of administrators, colleagues, and national and local authorities in order to provide effective instruction and solid results on education. Teachers own their classes; they are experts on learners' problems, student interests and real needs within their teaching contexts. As suggested by Giraldo (2014):

Teachers benefit from having someone help them to make sense of theory and their practice, who can articulate activities that help them reflect on teaching issues and who can guide them to find out what they do well and not as well. (p. 75)

However, Rayford (2010) stated that "a reflective practice involves thoughtfully considering one's own experiences in applying knowledge to practice while being coached by professionals in the discipline" (p. 27). Rayford's definition integrates an important dimension that constitutes the incorporation of reflection as a daily process to improve professional practice which is the importance of supporting language teachers with reflective training. It means, teachers are not familiar with the reflective progression, they are not used to being observed and when it happens they can get frustrated or nervous (Jerez, 2008).

Al-Issa and Al-Bulushi (2010) acknowledge that "a climate conducive to reflection should be developed through encouraging students to complete these reflective tasks for learning purposes, as they are being asked to write about what they know and do not know" (p. 48). To become reflective, teachers should be heard and their ideas and contributions must be considered within the educative context. On the one hand, it can be accomplished with the help of head administrators and other language teachers. On the other hand, language teachers should be aware of the real needs in a classroom; in that sense, reflection would encourage them to grow professionally throughout their own teaching experience. Reflection helps teachers assimilate what they do on a daily basis and accommodate their teaching instructions into new classroom practices. However, reflection also requires time and effort from teachers.

\section{In-Service Teachers Training}

Reflective teaching attained through professional development programs has been taken as a way to improve the professional practices of English language teachers who regard professional development "as a way to innovate, update their pedagogy and change their actions" (Jerez, 2008, p. 108). In general terms, and drawing from the content analysis, involving teachers in professional development programs focused on reflective teaching gives them benefits to change their perception and beliefs towards English language education that 
will finally reveal a whole transformation of the teacher not only within the classroom but also will help them raise their self-esteem, confidence, and their competence to create new approaches to education.

\section{Conclusions}

The content analysis of the 23 selected research studies shows that there is a significant contribution if reflective teaching strategies are implemented in the daily teaching practice. It also reveals that reflective teaching may become a professional development path that should be implemented according to each particular teaching context. The engagement of English language teachers in consistent activities of reflection, the understanding of the extent of teachers' motivation-including their attitudes and perceptions about language education - and self-examination would lead to a better understanding of English language education and comply with a broadened understanding of how students can actually become better language users. Teachers can apply reflection individually in a way that they feel more confident and do not have the perception that someone is judging their job, or cooperatively if they want to receive someone else's feedback.

The aim of professional development programs is focused on the improvement of teachers' actions to achieve effective outcomes of English language learners. This means that if language teachers are conscious of an effective language education, bearing in mind how learners learn, the results would easily be seen in the classroom. In particular, promoting active and viable professional development for English language teachers in Colombia is essential to provide language teachers with a pertinent professional development where their suggestions, proposals, real needs, and reflection of the actions taken will be heard. However, as said above, becoming a reflective teacher is not an easy process; it requires support, time, and effort.

It is also important to mention here that when in-service teachers are aware of the need of challenges, they develop their creativity and start implementing a variety of options to distinguish what is happening in their classroom in relation to the students learning process and set future goals or activities. For example, based on the literature review, by reflecting, in-service teachers would benefit from having "opportunities for [them] to make sense of theory and to criticize and use it meaningfully for classroom contexts" (Giraldo, 2014, p. 75).

Through the exploration it was also found that reflection offered the possibility for inservice teachers to interact collaboratively to enhance communication in the classroom and with other members of the school community. The reflective strategies were selected based on the fact that English language teachers are busy making many decisions in the classroom; 
as a consequence, in-service teachers may perceive a connection between what they face in the classroom and how they can address issues in it.

Based on the research findings, the application of reflective teaching has demonstrated how efficient it can be in the improvement of the knowledge base and English language teachers' competence. Mizell (2010) stated that “effective professional development enables educators to develop the knowledge and skills they need to address students' learning challenges. To be effective, professional development requires thoughtful planning followed by careful implementation with feedback to ensure it responds to educators' learning needs" (p. 10). Following Mizell's perspective, professional development programs should be supported by experienced educators in order to provide English language teachers with the right assessment.

Another positive aspect to mention in relation to reflective teaching and the improvement of professional practices has to do with attitudes and perceptions in-service teachers can have at the beginning of a selection of any reflective strategy; it means they can be nervous and/or anxious when realizing how effective or not their teaching can result from the reflection process. However, it was observed that when reflection becomes a habit, teachers start to comprehend the constant need to reflect and update challenges in the classroom. In this way, and based on Jerez (2008), they also "develop certain skills to become reflective such as to start working with colleagues, communicate ideas, look critically at their actions and evaluate the process they were following" (p. 110). In that sense, teachers need good communication with their colleagues and must be encouraged and supported by school administrators and principals regarding the provision of resources and the motivation to incorporate reflection as a routine. As Rayford (2010) argues: "establishing a supportive environment and developing a shared vision were important to employ reflective practices" (p. iv). In order to become more reflective towards teaching to enrich professional practices, it is necessary to develop common objectives not only among teachers and administrators, but also involving parents to improve students' English language level which is, in a way, one of the Colombian education authorities' goals. Also, it is imperative to note that thanks to reflection, a school community can consolidate reflective teaching as a means to create a supportive learning environment within the academic community.

In summary, the uses of different reflective teaching strategies are useful elements to improve English teaching professional practice. The strategies included in this studyjournals, lesson reports, audio and video recording, and self-monitoring methods_constitute an important starting point for in-service teachers who can analyze critically, raise awareness on their performance and become classroom researchers. It is evident that at the beginning of any reflective teaching implementation it could be a challenge because it requires time, effort and support. 


\section{References}

Ahmad, I., Said, H. B., Zeb, A., Rehman, S., Ahmad, S., \& Khan, W. (2013). How reflective practice improves teachers' classroom teaching skill? A case of community based schools in district Chitral, Khyber Pakhtunkhwa. Social Sciences and Humanities, 4(1), 73-81.

Al-Issa, A., \& Al-Bulushi, A. (2010). Training English language student teachers to become reflective teachers. Australian Journal of Teacher Education, 35(4), 41-64. https://doi.org/10.14221/ ajte. $2010 \mathrm{v} 35 \mathrm{n} 4.4$.

Álvarez, J. A. (2009). An exploration of Colombian EFL teachers' knowledge base through teachers' reflection (Master's thesis). Universidad Distrital Francisco José de Caldas, Bogotá, Colombia.

Ashour, S. (2008). Exploratory practice: An alternative tool for understanding life in the language classroom (Master's thesis). University of Exeter, UK.

Bailey, K. M. (1997). Reflective teaching: Situating our stories. Asian Journal of English Language Teaching, 7, 1-19.

Bett, H. K. (2016). The cascade model of teachers' continuing professional development in Kenya: A time for change. Cogent Education, 3, 1-9. https://doi.org/10.1080/233118 6X.2016.1139439.

Camacho, D. Z., Durán, L., Albarracin, J. C., Arciniegas, M. V., Martínez, M., \& Cote, G. E. (2012). How can a process of reflection enhance teacher-trainees' practicum experience? HOW, 19(1), 48-60.

Cárdenas, M. L., González, A., \& Álvarez, J. A. (2010). El desarrollo profesional de los docentes de inglés en ejercicio: algunas consideraciones conceptuales para Colombia [n service English teachers' profesional development: Some conceptual considerations for Colombia]. Folios, 31 , 49-68. https://doi.org/10.17227/01234870.31 folios49.67.

Castro, A. Y., \& Martínez, L. (2016). The role of collaborative action research in teachers' professional development. Profile: Issues in Teachers' Professional Development, 18(1), 39-54. https://doi. org/10.15446/profile.v18n1.49148.

Christodoulou, I. (2010). Teacher self-reflection (Diploma thesis). Masaryk University, Brno, Czech Republic.

Cote, G. E. (2012). The role of reflection during the first teaching experience of foreign language pre-service teachers: An exploratory-case study. Colombian Applied Linguistics Journal, 14(2), 24-34. https://doi.org/10.14483/udistrital.jour.calj.2012.2.a02.

Ditchburn, G. M. (2015). Remembering reflection in pre-service teachers' professional experience. Australian Journal of Teacher Education, 40(2). https://doi.org/10.14221/ ajte. $2015 \mathrm{v} 40 \mathrm{n} 2.7$.

Erginel, S. S.. (2006). Developing reflective teachers: A study on perception and improvement of reflection in pre-service teacher education (Doctoral dissertation). Middle East Technical University, Ankara, Turkey. 
Fandiño, Y. J. (2011, May). Reflective teaching in EFL teacher education programs. ASOCOPI Newsletter, 13-21. Retrieved from http://www.academia.edu/647444/Reflective_teaching in_EFL_teacher_education_programs.

Giraldo, F. (2014). The impact of a professional development program on English language teachers' classroom performance. Profile: Issues in Teachers' Professional Development, 16(1), 63-76. https://doi.org/10.15446/profile.v16n1.38150.

González, A. (2007). Professional development of EFL teachers in Colombia: Between colonial and local practices. Íkala, Revista de Lenguaje y Cultura, 12(1), 309-332.

Impedovo, M. A., \& Khatoon Malik, S. (2016). Becoming a reflective in-service teacher: Role of research attitude. Australian Journal of Teacher Education, 41(1). https://doi.org/10.14221/ ajte.2016v41n1.6.

Jerez, S. (2008). Teachers' attitudes towards reflective teaching: Evidences in a professional development program (PDP). Profile: Issues in Teachers' Professional Development, 10(1), 91-111.

Mathew, N. G. (2012). Reflective classroom practice for effective classroom instruction. International Education Studies, 5(3), 205-211. https://doi.org/10.5539/ies.v5n3p205.

Mizell, H. (2010). Why professional development matters. Oxford, US: Learning Forward.

Núñez, A., \& Téllez, M. F. (2015). Reflection on teachers’ personal and professional growth through a materials development seminar. HOW, 22(2), 54-74. https://doi.org/10.19183/ how.22.2.151.

Pedro, J. (2006). Taking reflection into the real world of teaching. Kappa Delta Pi Record, 42(3), 129132. https://doi.org/10.1080/00228958.2006.10516449.

Rayford, C. R. (2010). Reflective practice: The teacher in the mirror (Doctoral dissertation). University of Nevada, Las Vegas, USA.

Saylag, R. (2012). Self-reflection on the teaching practice of English as a second language: becoming the critically reflective teacher. Procedia: Social and Behavioral Sciences, 46, 3847-3851. https://doi.org/10.1016/j.sbspro.2012.06.158.

Schön, D. A. (1987). Educating the reflective practitioner. San Francisco, US: Jossey-Bass.

Soisangwarn, A., \& Wongwanich, S. (2014). Promoting the reflective teacher through peer coaching to improve teaching skills. Procedia: Social and Behavioral Sciences, 116, 2504-2511. https:// doi.org/10.1016/j.sbspro.2014.01.601.

Tairab, H. H. (2003). The role of reflection in facilitating pre-service primary school teachers' professional growth. Journal of Faculty of Education, 18(20), 1-21.

Trujillo, S. M. (2015). Reflective inquiry on strategic reading instruction (Master's thesis). Universidad de Antioquia, Medellín, Colombia.

Viáfara, J. J. (2005). The design of reflective tasks for the preparation of student teachers. Colombian Applied Linguistics Journal, 7, 53-74.

Zalipour, A. (2015). Reflective practice: Teaching development unit. Retrieved from https://www.waikato. ac.nz/_data/assets/pdf_file/0006/360861/Reflective-Practice-June-2015.pdf. 


\section{The Author}

Marian Lissett Olaya Mesa holds a BA in foreign languages from Universidad Pedagógica y Tecnológica de Colombia and an MA in English language teaching for selfdirected learning from Universidad de la Sabana (Colombia). She has been an English language teacher for nine years in which she has gained a lot of experience teaching English for engineering programs. She is currently the coordinator of the international language institute in the city of Sogamoso (Colombia). 


\section{Appendix: Protocol Proposal}

The purpose of this reflective teaching protocol is to provide teachers with an opportunity to grow professionally on their own by means of a set of reflective stages that can be conducted individually or with colleagues within a school. This protocol is designed to be implemented in a month. However, teachers have to bear in mind that reflective teaching is a process and must become a habit to provide concrete results. To reach the objective of a protocol the author of this study suggested the following stages based on the literature exploration carried out:

\section{Observation Stage}

1. Plan a 40 minutes lesson on the topic of your interest. Do it in your usual manner.

2. Set up the classroom in order to videotape your lesson.

3. When you are at home, in a calm area, watch the video and answer the following questions:

a). What were the aims of the lesson? Did you or your students reach them? How do you know that?

b) What roles did you play as a teacher within this lesson?

c) What difficulties did you have within this lesson?

d) How can you improve those difficulties next time? Set a suggestion list (e.g., look for articles or research papers that address those issues).

4. Ask a friend to watch the video; your friend must tell you about your weaknesses and strengths and some suggestions to improve your teaching.

5. Compare your suggestion list with your friend's advice and update a plan in order to improve on the issue you found.

\section{Writing Stage}

1. Keep a lesson report for four days in which you specify aims of the lessons, strategies you used to foster students learning process, your roles as teacher, the assessment and evaluation procedures, the outcomes, and the issues you may encounter.

2. Based on the lesson reports, write entries in your journal in which you reflect. Some guiding questions are: Are your lessons effective? Why/why not? Did you 
find the same weaknesses you found during the videotaping stage? Why do you think the same issues keep appearing?

\section{Action Plan}

1. After videotaping and writing on your performance in class, set up an action plan in order to provide solutions to the issues you encountered and to improve your lessons.

2. Put your plan in action and keep writing lesson reports daily and a journal weekly.

\section{Reflective Feedback}

You can answer this stage after a month of the implementation of your plan. Ask the following questions:

- Are you lessons different? How?

- Do your strategies encourage an effective students' learning process? Explain.

- Is your role as a teacher different?

- Do you consider that this RT process has shaped your professional practices? 